\title{
Ontological Promiscuity
}

\author{
Jerry R. Hobbs \\ Artificial Intelligence Center \\ SRI International \\ and \\ Center for the Study of Language and Information \\ Stanford University
}

\begin{abstract}
To facilitate work in discourse interpretation, the logical form of English sentences should be both close to English and syntactically simple. In this paper I propose a logical notation which is first-order and nonintensional, and for which semantic translation can be naively compositional. The key move is to expand what kinds of entities one allows in one's ontolozy, rather than complicating the logical notation, the logical form of sentences, or the semantic translation process. Three classical problems opaque adverbials, the diatinction between de re and de dicto belief reports, and the problem of identity in intensional contexts - are examined for the difficulties they pose for this logical notation, and it is shown that the difficulties can be overcome. The paper closes with statement about the view of semantics that is presupposed by this approsech.
\end{abstract}

\section{Motivation}

The real problem in aatural language processing is the interpretation of discourse. Therefore, the other apects of the total process should be in the service of discourse interpretation. This includes the semantic translation of sentences into logical form, and indeed the logical notation itself. Diecourse incerpretation processes, as I see them, are inferential processes that manipulate or perform deductions on logieal expressions encoding the information in the text and on other logieal expressions encodin: the speaker's and hearer's background knowledge. These considerationa lead to two principal criteria for a logical notation.

Criterion I: The notation should be a cloce to English as possible. This makes it easier to speeify the rules for transiation between English and the formal language, and also makes it easier to encode in logical notation facts we normally think of in Engiish. The ideal choice by this criterion is English itself, but it fails monumentally on the second criterion.

Criterion II: The notation should be syntectically simple. Since discourse processes are to be defined primarily in terms of manipulations performed on expressions in the lorgical notation, the simpler that notation, the easier it will be to define the diseourse operations.

The development of such a logical notation is usually taken to be a very bard problem. I believe this is because researehers have imposed upon themselves several additional constraints to adhere to stringent ontological scruples, to expiain a number of mysterious syntactic facts as a by-product of the notation, and to encode efficient deduetion techniques in the notation.
Most representational difficulties go away if one rejects these constraints, and there are good reasons for rejecting each of the constraints.

Ontological scruples: Researehers in philosophy and linguistics have typically restricted themselves to very few (although a strange assortmeat of) kinds of entities - physical objects, numbers, sets, times, possible worlds, propositions, events, and situations - and al of these but the first have been controversial. Quine has been the greatest exponent of ontological chastity. His argument is that in any scientific theory, "we adopt, at least insolar as we are reasonable, the simplest conceptual scheme into which the disordered fragments of our experience can be fitted and arranged." (Quine, 1953, p. 16.) But he goes on to say that "simplicity ... is not a clear and unambiguous idea; and it is quite capable of presenting a double or multiple standard." (/bid., p. 17.) Minimizing kinds of entities is not the only way to achieve simplicity in a theory. The aim in this enterprise is to achieve simplicity by minimizing the complexity of the rules in the system. It turns out this can be achieved by multiplying kinds of entities, by allowing as an entity everything that can be referred to by a noun phrase.

Syntactic explanation: The argument here is easy. It would be pleasant if an explanation of, say, the syntactic bebavior of count nouns and mass nouns fell out of our underlying ontological stricture at no extra cost, but if the extra cost is great complication in statements of discourse operations, it would be quite unpleasant. In constructing a theory of discourse interpretation, it doesn't make sense for us to tie our hands by requiring syntectic explanations as well. The problem of discourse is at least an order of magaitude harder than the problem of syntax, and syntax shouldn't be in the driver's seat.

Efficient deduction: There is a long tradition in artificial intelligence of building control information into the notation. and indeed much work in knowledge representation is driven by this consideration. Sementic networks and otber notational systems buiit around bierarchies (Quillian, 1068; Simmons, 1973; Hendrix, 1975) implieitly assign a low cost to certain types of oyllogintic reaconiog. The KL-ONE representation language (Sebmolze and Brachman, 1982) bas a variety of notational devices, each with an associated efficient deduction procedure. Hayes (1979) has argued that frame representations (Minsky, 1975; Bobrow and Winograd, 1977) should be viewed as sets of predicate calculus axioms together with a control component for drawing certain kinds of inferences quickly. In quite a different vein, Moore (1980) uses a possible worlds notation to model knowledge and action in part to avoid inefficiencies in theorem- 
proving.

By contrast, I would argue against building efficiencies into the notation. From a psychological point of view, this allows us to abstract away from the details of implementation on a particular computational device, increasing the generality of the the ory. From a technological point of view, it reflects a belief that we must first determine empirically the most common classes of inferences required for discourse processing and only then seek algorithms for optimizing them.

In this paper I propose a flat logical notation with an ontolog. ically promiscuou semanties. One's fint naive guess as to how to represent a simple sentence like

A boy builds a boat.

is as follows:

$$
(\exists x, y) \text { build }(x, y) \wedge \text { boy }(x) \wedge \text { boat }(y)
$$

This simple approach seems to break down when we encounter the more difficult phenomens of natural language, like tense, intensional contexts, and adverbials, an in the sentence

A boy wanted to build a boat quickly.

These phenomena have led students of language to introduce significant complications in their logical notations for representing sentences. My approach will be to maintain the syntactic simplicity of the logical notation and expand the theory of the world implicit in the semantics to accommodace this simplicity. The representation of the above sentence, as is justified below, is

$$
\begin{gathered}
\left(\exists e_{1}, e_{2}, e_{3}, x, y\right) P \text { ast }\left(e_{1}\right) \wedge \text { want }\left(e_{1}, x, e_{2}\right) \wedge q_{\text {quick }}\left(e_{2}, e_{3}\right) \\
\wedge \text { build }\left(e_{3}, x, y\right) \wedge \text { boy }(x) \wedge \text { boat }(y)
\end{gathered}
$$

That is, $e_{1}$ oceurred in the past, where $e_{1}$ is $x$ 's wanting $e_{2}$, which is the quickness of es. which is $z$ 's building of $y$, where $x$ is a boy and $y$ is a boat.

In brief, the logical form of natural language sentences will be a conjunction of atomic predications in which all variables are existentially quantified with the widest possible scope. Predicates will be identical or nearly identical to natural language morphemes. There will be no functions, functionals, nested quantifiers, disjunction, negation, or modal or intensional operators.

\section{The Logical Notation}

Davidson (1967) proposed a treatment of action sentences in which events are treated as individuals. This facilitated the representation of sentences with time and place adverbials. Thus we can view the sentences

John ran on Monday.

John ran in San Francisco.

as asserting the existence of a running eveat by John and asserting a relation between the event and Monday or San Francisco. We can similarly view the sentence

John ran slowly.

as expressiag an attribute about a nunning event. Treating events as individuals is also useful because they can be arguments of statements about causes:
Because he wanted to get there first, John ran.

Because John ran, he arrived sooner than anyone else.

They can be the objects of propositional attitudes:

Bill was surprised that John ran.

Finally, this approach accomodates the facts that events can be nominalized and can be referred to pronominally:

John's running tired him out.

John ran, and Bill saw it.

But virtually every predication that can be made in natural language can be specified as to time and place, be modified adverbially, function as a cause or effect of something else, be the object of a propositional attitude, be nominalized, and be referred to by a pronoun. It is therefore convenient to extend Davidson's approach to all predications. That is, corresponding to any predication that can be made in natural langlage, we will say there is an event, or state, or condition, or situation. or "eventuality", or whatever, in the world that it refers to. This approach might be called "ontological promiseuity". One abandons all ontological scruples.

Thus we would like to have in our logical notacion the possibility of an extra argument in each prectication referring to the "condition" that exists when that predication is true. However. especially for expository convenience, we would like to retain the option of not specifying that extra argument when it is not needed and would only get in our way. Hence. I propose a logical notation that provides two sets of predicates that are systematically related, by introduring what might be called a "nominalization" operator'. ('orresponding 10 every "1-ary predicate $p$ there will be an $n+1$-ary predicalc $p^{\prime}$ whose lirst argument can be thought of as the condition that holds when $p$ is ime of the subsequent arguments. Thus, if run(J) ments that John runs, ruf' $(E, J)$ means that $E$ is a running event by John. or John's running. If slippery $(F)$ means that floor $F$ is slippery, then slippery' $(E, F)$ means that $E$ is the condition of $F$ 's being slippery, or $F^{\prime}$ s siipperiness. The effect of this notational maneuver is to provide handiles by which various prerlications can be grasped by higher predications. A similar approach has heen used in many Al systems.

In diseourse one not only makes predieations about such ephemera as events, states and conditions. One also refers to encities that do not actually exist. Our notation must thus have a way of referring to such entities. We therefore take our model to be a Platonic universe which contains everything that can be spoken of - objects, events, states, conditions - whether they exist in the real world or not. It then may or may not be a property of such entities that they exist in the real world. In the sentence

\section{(1) John worships Zeus,}

the worshipping event and John, but not Zeus, exist in the real world, but all three exist in the (overpopulated) Platonic universe. Similarly, in

John wants to fly. 
John's flying exists in the Platonic universe but not in the real world. ${ }^{1,2}$

The logical notation then is just first-order predicate calculus, where the universe of discourse is a rich set of individuals, which are real, possible and even impossible objects, events, conditions, eventualities, and so on.

Existence and truth in the actual universe are treated as predications about individuals in the Platonic universe. For this purpose, we use a predicate Exist. The formula Exist(JOHN) says that the individual in the Platonic universe denoted by JOHN exists in the actual universe. The formula

\section{(2) $E \operatorname{zist}(E) \wedge \operatorname{run}^{\prime}(E, J O H N)$}

says that the condition $E$ of John's nunning exists in the actual universe, or more simply that "Johu runs" is true. or still more simply, that Jobn runs. A shorter way to write it is $\operatorname{run}(J O H N)$.

Although for a simple sentence like "John runs", a logical form like (2) seems a bit overblown, when we come to real sentences in English discourse with their variety of tenses, modalities and adverbial motifiers, the more elaborated logical form is necessary. Adopting the notation of (2) has the effert of splitting a sentence into its propositional content - run' $(E, J O H I N)$ and its assertional claim - Exist $(E)$. This frequently turns out to be useful, as the latter is often in doubt until substantial work has been done by discourse interpretation processes. An entire sentence may be embedded within an indirect prool or other extended counterfactual.

We are now in a position to state formally the systematic relation between the unprimed and primed predicates as an axiom schema. For every n-ary predicate $p$.

$$
\left(\forall x_{1}, \ldots, x_{n}\right) p\left(x_{1}, \ldots, x_{n}\right) \supset(\exists e) E x i s t(e) \wedge p^{\prime}\left(e, x_{1}, \ldots, x_{n}\right)
$$

That is, if $p$ is true of $x_{1}, \ldots, x_{n}$, then there is a condition $e$ of $p$ 's being true of $x_{1}, \ldots, x_{n}$, and $e$ exists. Conversely,

$$
\left(\forall e, x_{1}, \ldots, x_{n}\right) E \operatorname{rist}(e) \wedge p^{\prime}\left(e, x_{1}, \ldots, x_{n}\right) \supset p\left(x_{1}, \ldots, x_{n}\right)
$$

That is. if $e$ is the condition of $p$ 's being tmie of $x_{1}, \ldots, x_{n}$, and $e$ exists, then $p$ is true of $x_{1}, \ldots, x_{n}$. We can enmpress these axiom schemas into one formula:

$$
\text { (3) }\left(\forall x_{1}, \ldots, x_{n}\right) p\left(x_{1}, \ldots, x_{n}\right) \equiv(\exists e) E \text { siat }(e) \wedge p^{\prime}\left(e, f_{1}, \ldots, x_{n}\right)
$$

A sentence in English asserts the existence of one or more eventualities in the real world, and this may or may not imply the existence of other individuals. The logical form of sentence (1) is

$$
E_{x i s t}(E) \wedge \text { worship' }(E, J O H N, Z E V S)
$$

This implies Exist(JOHN) but not Exist(ZEIIS). Similarly, the logical form of "John wants to fly" is

\footnotetext{
'One need not adhere to Platonism to aceept the Platunic universe. It e an be viewed as a socially conatituted, or conventional, construc:ion, which is neverthelea highly constrained by the way the (not directly accessible) material world is. The degree of constraint is variable. We are more constrained by the material worid to believe in trees and chain, less so to betieve in patriotiam or ghosts.

${ }^{2}$ The reader might choose to think of the Platonic universe at the universe of possible individuals, although I do not want to exclude lorically im. poasible individuals, such a the condition John believes to exist when he believes $6+7=15$.

${ }^{3}$ MeCarthy (1977) employs a simtlar technique.
}

\section{$E_{\text {rist }}\left(E_{2}\right) \wedge \operatorname{want}^{\prime}\left(E_{2}, J O H N, E_{1}\right) \wedge f y^{\prime}\left(E_{1}, J O H N\right)$}

This implies $E_{x i s t}(J O H N)$ but not $E_{x i s t}\left(E_{1}\right)$. When the existence of the condition corresponding to some predication implies the existence of one of the arguments of the predication, we will say that the predicate is transparent in that argument, and opaque otherwise." Thus, worship and want are transparent in their first arguments and opaque in their second arguments. In general if a predicate $p$ is transparent in its $n$th argnıment $x_{\text {, this }}$ can be encoded by the axiom

$$
(\forall e, \ldots, x, \ldots) p^{\prime}(e, \ldots, x, \ldots) \wedge E_{x i s t}(e) \supset E_{\operatorname{rist}}(x)^{5}
$$

That is, if $e$ is p's being true of $x$ and $e$ exists, then $x$ exists. Equivalently,

$$
(\forall \ldots, x, \ldots) p(\ldots, x, \ldots) \supset \operatorname{Erist}(x)
$$

In the absence of such axioms, predicates are assumed to be opautue.

The following sentence illustrate's the extent 10 which we must have a way of representing existent and nonevintent wate's and events in ordinary diseourse.

(4) The governmenc has repeatedly refused to deny that P'rime Miniscer Margaret thateher vetoed the ( hannel Tunnel at her summit merting with President Mitterand on 18 . May. as New Srientist revealed last week."

In addition to the ordinary individuals. Markaret Thateher and President Mitterand and the corporate entity Vet" Sorentist.

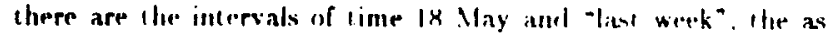

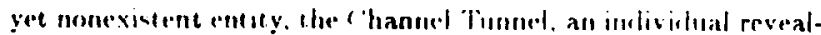
ing event. and the romplex evente of the summit meeting, which actually ocrurred. a set of real refusals distributed across time in a particular way. a dervial event which did not occur. and a vetoing evertt which may or may not have occurred.

Let us take Pastl tis) to mean that fia existed in the past and Perfert $\left(F_{1}\right)$ to inean what the perfort tense means, roughly. that $E_{1}$ existed in the past and may not set be completert. The representation of just the verb, nominalizations. advertials and terises of sentence $(1)$ is as follows:

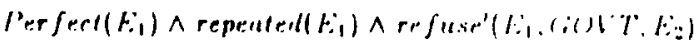

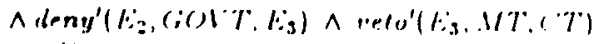

$$
\begin{aligned}
& \wedge a t^{\prime}\left(E_{1}, E_{3}, C_{3}\right) \wedge \text { meet }\left(E_{3}, V T, l \cdot M\right)
\end{aligned}
$$

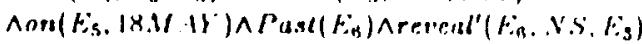

$$
\begin{aligned}
& \wedge \text { last-week }\left(t_{i+1}\right)
\end{aligned}
$$

Of the various entities refereed in. the semtetuce. via unprimed predicaters. asserts the esiscerece of a typiral refusal $f_{1}$ in a set

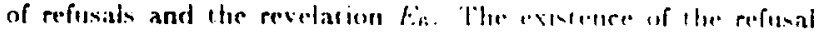

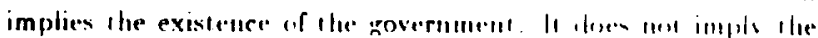

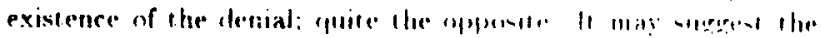

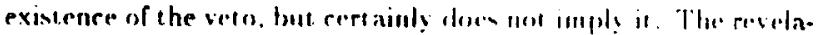
tion $E_{B}$, however, implies the existence of both the vey Srirntist

\footnotetext{
"More properiy, we should say "existentially transparent" and "existen. tiaily opaque", since this notion doms ant coincide pxactly with referential traneparency.

BQuantification in this notation is aiways nver entities in the Platonic uni. verse. Existence in the real world is expressed by predicates, in particular the predicate Erist.

This sentence is taken from the New Scientict, June 3, 1982 (p. (332). I am indebted to Paul Martin for calling it to my actention.
} 
$N S$ and the at relation $E_{4}$, which in turn implies the existence of the veto and the meeting. These then imply the existence of Margaret Thatcher $M T$ and President Mitterand $P M$, but not the Channel Tunnel CT. Of course, we know about the existence of some of these entities, such as Margaret Thatcher and President Mitterand, for reasons other than the transparency of predicates.

Sentence (4) shows that virtually anything can be embedded in a higher predication. This is the rewon, in the logical notation, for flattening everything into predications about individuals.

There are four serious problems that must be dealt with if this approach is to work - quantifiers, opaque adverbials, the distinction between de re and de dicto readings of belief reports, and the problem of identity in intensional contexts.

I have described a solution to the quantifier problem elsewhere (Hobbs, 1983). Briefly, universally quantified variables are reified typical elements of sets, existential quantification inaide the scope of universally quantified variables are bandled by means of dependency functions, and the quantifier structure of sentences is encoded in indices on predicates. In this paper I will address only the other three problems in detail.

\section{Opaque Adverbials}

It seems reasonably natural to treat transparent adverbials as properties of events. For opaque adverbials, like "almost", it seems lese astural, and one is inclined to follow Reichenbach (1947) in treating them a functionals mapping predicates into predicates. Thus,

John is almost anan.

would be represented

$$
\text { almost }(\operatorname{man})(J)
$$

That is, almost maps the predicate man into the predicate "almost a man", which is then applied to John.

This representation is undesirable for our purposes since it is not first-order. It would be preferable to treat opaque operators as we do tranaparent ones, a propertie of events or conditions. The sentence would be represented

$$
\operatorname{almost}(E) \wedge \operatorname{man}^{\prime}(E, J)
$$

But does this get us into dificulty?

First note that this representation does not imply that John is a man, for we have not asserted $E$ 's existence in the real worid, and almost is opeque and does not imply its arsument's existence.

But is there enough information in $E$ to allow one to determine the truth value of almost $(E)$ in isoletion; without appeal to other facts? The anower is that there could be. We ran conacruct a model in which ior every functional $F$ there is a corresponding equivalent predicate $q$, such that

$$
(\forall p, r)\left(F(p)(x) \equiv(\exists e) q(e) \wedge p^{\prime}(e, x)\right)
$$

The existence of the model shows that this condition is not neeessarily contradictory.

Let the universe of discourse $D$ be the class of finite sets built out of a finite set of urelements. The interpretation of a constaat
$X$ will be some element of $D$; call it $I(X)$. The interpretation of a monadic predicate $p$ will a subset of $D$; call it $I(p)$. Then if $E$ is such that $p^{\prime}(E, X)$, we define the interpretation of $E$ to be $\langle I(p), I(X)\rangle$.

Now suppose we bave a functional $F$ mapping predicates into predicates. We can define the corresponding predicate $q$ to be such that

$q(E)$ is true iff there are a predicate $p$ and a constant $X$ where the interpretation of $E$ is $\langle I(p), I(X)\rangle$ and $F(p)(X)$ is true.

The fact that we can define such a predicate $q$ in a moderately rich model means that we are licensed to treat opaque adverbials as properties of events and conditions.

The purpose of this exereise is only to show the viability of the approsch. I am not claiming that a running event is an ordered pair of the runner and the set of all runners, although it should be harmiess enough for those irredeemably committed to set-theoretic semantics to view it like that.

It should be noted that this treatment of adverbials has consequenees for the individuating criteria on eventualities. We can say "John is almost a man" without wishing to imply "John is aimost a mammal," so we would not want to say that John's being a man is the same condition as his being a mammal. We are lorced, though not unwillingly, into a position of individuating eventualities according to very fine-grained criteria.

\section{De Re and De Dicto Belief Reports}

The next problem concems the distinction (due to Quine (1956)) between de re and de dicto belief reports. A belief report like

(5) John believes a man at the next table is a spy.

has two interpretations. The de dirto interpretation is likely in the eireumstance in which John and some man are at adjacent tables and John observes suspicious behavior. The de re interpretation is likely if some man is sitting at the table next to the apeaker of the senteace, and Jobn is nowhere around but knows the man otherwise and suspects him to be a spy. A sentence that very nearly forees the de re reading is

John believes Bill's mistress is Bill's wife.

wheres the sentence

John believes Russian consulate employers are spies.

strongly indicates a de dicto reading. In the de re reading of (5), John is not necessarily taken to know that the man is in fact at the next table, but he is normally assumed to be able to identify the man somehow. More on "identify" helow. In the de dieto reading John believes there is a man who is both at the next table and a spy, but may be otherwise unable to identify the man. The de re reading of (5) is usually taken to support the inference

(6) There is someone John believes to be a spy.

whereas the de dicto reading supports the weaker inference

(7) John believes that someone is a spy.

This example is due to Moore and Bendrix (1982). 
As Quine has pointed out, as usually interpreted, the first of these sentences is false for most of us, the second one true. A common notational maneuver (though one that Quine rejects) is to represent this distinction as a scope ambiguity. Seatence $(6)$ is encoded as (8) and (7) as (9):

(8) (ヨx)believe $(J$, spy $(x))$

\section{(9) believe( $J,(\exists x) \operatorname{spy}(x))$}

If one adopts this notacion and stipulates what the expressions mean, then there are certainly distinct ways of represeating the two sentences. But the interpretation of the two expressions is not obvious. It is not obvious for example that (8) could not cover the case where there is an individual such that John believes him to be a spy but has never seen him and knows absolutely nothing else about him - not his name, nor his appearance. nor his location at any point in time - beyond the fact that he is a spy.

In fact. the notation we propose takes (8) to be the most neutral representation. Since quantification is over entities in the Platonic universe. (8) says that there is some ontity in the Platonic universe such that John believes of that entity that it is a spy. Expression (8) commits us to no other heliefs on the part of John. When understood in this way, expression (8) is a representation of what is conveyed in a de dirto betief report. Translated into the flat notation and introducing a constant for the existentially quantified variable. (8) beenmes

(10) believe( $J, P) \wedge \operatorname{spy}^{\prime}(P, S)$

Anything else that John believes about this entity must be stated explicitly. In particular, the de dicto reading of (5) would be represented by something like

\section{(11) believe( $J, P) \wedge \operatorname{spy}^{\prime}(P, S) \wedge$ believe $(J, Q) \wedge a l^{\prime}(Q, S, T)$}

where $T$ is the next table. That is, John believes that $S$ is a spy and that $S$ is at the next table. John may know many other properties about $S$ and still fall short of knowing yho the spy is. There is a range of possibilities for John's knowledge. from the bare statements of $(10)$ and (11) that correspond to a de dictn reading to the full-blown knowledge of $S$ 's idencity that is normally present in a de re reading. In fact, an FBI agent would progress through just such a range of belief states on his way to identifying the spy.

To state John's knowledge of $S$ 's identity properly, we would have to state explicitly John's belief in a potentially very large collection of properties of the spy. To arrive at a suscinct way of representing knowledge of identity in our nntation. let us consider the two pairs of equivalent sentences:

What is that?

Identify that.

The FBI doesn't know who the spy is.

The FBI doesn't know the spy's identity.

The answer to the question "Who are you?" and what is required before we can say that we know who someone is or that we know their identity is a bighly context-dependent matter. Several years ago, before I bad ever seen Kripke, if someone had asked me whether I knew who Saul Kripke was, I wouid have said. "Yes. He's the author of Noming and Necessity." Then once I was at a workshop which I knew was being attended by
Kripke, but I didn't yet know what he looked like. If someone had asked me whether I knew who Kripke was, I would have had to say, "No." The relevant property in that context was not his authorship of some paper, but any property that distinguished him from the others present, such as the man in the back row holding a cup of coffee"

Knowledge of a person's identity is then a matter of knowing some context-dependent essential property that serves to identify that person for present purposes - that is, a matter of knowing who he or she is.

Therefore, we need a kind of place-holder predicate to stand for this essential property, that in any particular context can be specified more precisely. It happens that finglish has a morpheme that serves just this function - the morpheme "wh". Let us then posit a predicate wh that stands for the contextually determined property or conjunction of properties that would count as an identification in that particular context.

The de re rearling of (i) is generally taken to include Johns: knowledge of the identity of the alleriged spy. Assuming this, a de re belief report would be represented as a conjunction of two beliefs, one for the inain prediration and the other expressing knowledge of the esserntial property. the what-ness. of the argiment of the predication.

believe( $J, P) \wedge s p y^{\prime}(I, X) \wedge$ inow $(J, !) \wedge w^{\prime} h^{\prime}(Q, X)$

That is. John believes $S t$ is a yly and folm knows who $t 5$ is

However, let us probe this tictinetion just a little more deeply and in particular call into culewtun wherluer knowledge of identity is really part of the meaning of the sentence in the de re reading. The representation of the de dirto reading of 5 , I have said. is

(12) believe $(J, P) \wedge s p y^{\prime}(P, S) \wedge$ beliere $(J . Q) \wedge a t^{\prime}(Q, S . T)$

Let us represent the de re reading an

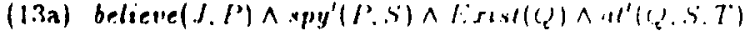

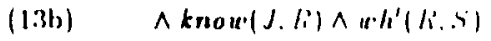

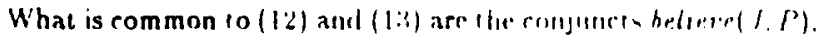

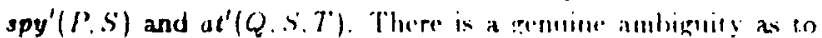
whether $Q$ exists in the eral world (de: re) or is morely believed by John (de dic(o). In addition. (1:i) inchude. the conjuncts $k n o w(J, R)$ and $w h^{\prime}\left(/ R . S^{\prime}\right)$ - line $(13$,$) .$

But are these necessarily part of the de re interpretalud of

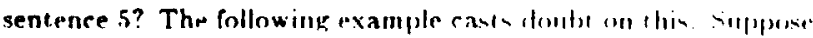

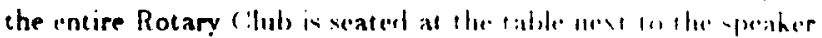

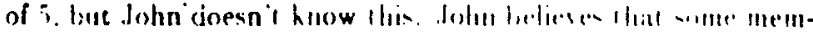

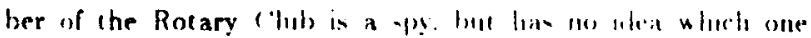
sentence 5 describes this sitwalon. ant only $(1: 3)$ holks. not (13h) and not (12). Judements are somerimes uturertain as to whether sentence 5 is appropriate in the'se circumstances. but it is certain that the sentence

John believes someone at the next table is a spy.

is appropriate, and that is sufficient for the argument.

It seems then that the conjuncts $k n o w(J, R)$ and $w h^{\prime}(R, S)$ are not part of what we want in the initial logical form of the sentence, but only a very common conversational implicature. The reason the implicature is very common is that if

\footnotetext{
A nother way of putting it: they are not part of the literal meaning of the
} sentence. 
John doesn't know that the man is at the next table, there must be some other description under which John is familiar with the man. The story I just told provides such a description, but not one sufficient for identifying the man.

This analysis is attractive sinee it allows us to view the de re. de dicto distinetion problem as just one instance of a much more general problem, namely, the existential status of the grammatically subordinated material in sentences. Generally, such material takes on the tense of the sentence. Thus, in

The boy built the boat.

a building event by $x$ of $y$ takes place in the past, and we assume that I was a boy in the past, at the time of the building. But in

Many rich men studied computer science in college.

the most aatural reading is not that the men were rich when they were studying computer science but that they are rich now. In

The flower is artificial.

there is an entity $x$ which is described as a flower, and $x$ exists, but its "flower-ness" does not exist in the real worid. Rather, it is a condition which is embedded in the opaque predicate "artificial".

It was stated above that the representation (10) for the de dicto reading conveys no properties of $S$ other than that John believes him to be a spy. In particular, it does not convey $S$ 's existence in the real world. $S$ thus refers to a possible individual, who may turn out to be actual if, for example, John ever comes to be able to identify the person whom he believes to be the spy. or if there is some actual spy who has given John good cause for his suspicions.

However, $S$ may not be actual, only possible. Suppose this is the ease. One common objection to possible individuals is that they may seem to violate the Law of the Excluded Middle. Is $S$ married or not married? Our intuition is that the question is inappropriate, and indeed the answer given in our formalism has this flavor. By axiom (3), married( $S)$ is really just an ab. breviation for married" $(E, S) \wedge E x i s t(E)$. This is false, for the existence of $E$ in the real world would imply the existence of $S$. So morried $(S)$ is also false. But its falsity has nothing to do with $S$ 's marital status, only his existential stacus. The predication unmarried $(S)$ is false for the same reason. The primed predicates are basic, and for them the problem of the excluded middle does not arise. The predication married $(E, S)$ is true or false depending on whether $E$ is the condition of $S$ 's being married. An unprimed, transparent predicale carries along with it the existence of its arguments, and it can fail to be true of an entity either through the entity being actual but not having that property or through the nonexistence of the entity.

\section{Identity in Belief Contexts}

The final problem I will consider arises in de dicto belief reports. It is the problem of identity in intensional contexts, raised by Frege (1892). One way of stating the problem is this. Why is it that if

(14) John believes the Evening Star is rising.

and if the Evening Star is identical to the Morning Star, it is not necessarily true that
(15) John believes the Morning Star is rising

By Leibniz's Law, we ought to be able to substitute for an entity any entity that is identical to it.

This puzzle survives translation into the logical notation, if John knows of the existence of the Morning Star and if proper names are unique. The representation for (the de dicto reading of) sentence (14) is

(16) believe $\left(J, P_{1}\right) \wedge$ rise' $\left(P_{1}, E S\right) \wedge$ believe $\left(J, Q_{1}\right)$ $\wedge$ Evening-Star $\left(Q_{1}, E S\right)$

John's belief in the Morning Star would he represented

believe $\left(J, Q_{2}\right) \wedge$ Morning-Slar $\left(Q_{2}, M S\right)$

The existence of the Evening Star and the Morning Star is expressed by

$$
E_{\text {rist }}\left(Q_{1}\right) \wedge \operatorname{Erist}_{\text {sis }}\left(Q_{2}\right)
$$

The uniqueness of the proper name "Evening Star" is expressed by the axiom

$$
(\forall x, y) \text { Evening-Star }(x) \wedge \text { Evening-Star }(y) \supset x=y
$$

The identity of the Evening Star and the Moming Star is expressed

$$
(\forall x) \text { Evening-Star }(x) \equiv \text { Morning-Star }(x)
$$

From all of this we can infer that the Moming Star MS is also an Evening Star and hence is identical to $\mathrm{ESS}$, and hence can be substiluted inco rise' $\left(P_{1}, E S\right)$ to give rise' $\left(P_{1}, M S\right)$. Then we bave

$$
\begin{gathered}
\text { believe }\left(J, P_{1}\right) \wedge \operatorname{rise}^{\prime}\left(P_{1}, M S\right) \wedge \text { believe }\left(J, Q_{2}\right) \\
\wedge M \text { orning-Star }\left(Q_{2}, M S\right)
\end{gathered}
$$

This is a representation for the paradoxical sentence (15).

There are three possibilities for dealing with this problem. The first is to discard or restrict lecibniz's Law. The second is to deny that the Fvening Star and the Morning Star are identical as entities in the Platonic universe; they only happen to be identical in the real world. and that is not sufficient for intersubstitutivity. The third is to deny that expression (16) represents ventence (14) because "the Fivening Star" in (14) does not refer to what it seems to refer to.

The first possibility is the approach of researchers who treat belief an operator rather than as a predicate, and then re. strict substitution inside the operator.? We cannot avail ourselves of this. solution because of the flatness of our notation. The predicate ruse is surely referentially transparent, so if $E S$ and $M S$ are idencical, MS can be substituted for E:S in the expression rise' $\left(P_{1}, f . S\right)$ to yive rise' $\left(P_{1}, M / S\right)$. Then the expression beiieve $\left(J, P_{1}\right)$ would not even require substitution to be a belief about the Morning Star.

In any case, this approach does not seem wise in view of the central importance played in discourse interpretation by the identity of differently presented entities, i.e. by coreference. Free intersubstitutibility of identicals seems a desirable property to preserve.

The second possible answer to Frege's problem is to say that in the Platonic universe, the Moming Star and the Evening Star

-This is a purely syntactic approach, and when one tries to construct a semantics for it, one is generally driven to the third possibility. 
are different entities. It just happens that in the real wortd they ane identical. But it is not true that $E S=M S$, for equality, like quantification, is over entities in the Platonic universe. The fact that $E S$ and $M S$ are identical in the real wortd (call this relation rwoidentical) munt be stated explicitly, say, by the expresaion

ro-identical( $E S, M S)$

or more properly,

$$
(\forall x, y) \text { Morning-Star }(x) \wedge \text { Evering-Star }(y)
$$$$
\supset \text { ro-identical }(x, y)
$$

For resooning about "w-ideatieal" entities, that is, Platonic eatities that are identieal in the real world, we may take the following approach. Subatitution in referentially transparent contexts would be achieved by use of the axiom sehema

(17) $\left(\forall e_{1}, e_{3}, e_{4}, \ldots\right) p^{d}\left(e_{1}, \ldots, e_{3}, \ldots\right) \wedge$ rwoidentical $\left(e_{4}, e_{3}\right)$ $\supset\left(\exists e_{2}\right) p^{\prime}\left(e_{2}, \ldots, e_{4}, \ldots\right) \wedge$ rv-identical $\left(e_{2}, e_{1}\right)$

where $e_{g}$ is the kth argumenc of $p$ and $p$ is referentially trangparent in its kth argument. That is, if $e_{1}$ is p's being true of $e_{3}$ and $e_{3}$ and $e_{4}$ are identical in the real wortd, then there is a condition $e_{2}$ of $p$ 's being true of $e_{4}$, and $e_{2}$ is identical to $e_{1}$ in the real world. Subotitution of "rw-identicals" in a condition results not in the same condition but in an "Nw-identical" condition. There would be such an axiom for the first argumeat of believe but not for its referentially opeque seeond argument.

Axioms will expreas the fact thas ravidentical in an equivaleace relasion:

$$
\begin{aligned}
& (\forall z) \text { rw-identical }(x, z) \\
& (\forall z, y) \text { rovidentical }(x, y) \supset \text { ro-identical }(y, z) \\
& (\forall x, y, z) \text { rwoidentical }(x, y) \wedge \text { rooidentical }(y, z) \\
& \supset \text { rovidentical }(x, s)
\end{aligned}
$$

Finally, the following exiom, together with axiom (17), would exprew Laibriz's Law:

$$
\left(V e_{1}, e_{3}\right) \text { rw-identical }\left(e_{1}, e_{2}\right) \supset\left(\operatorname{Exist}\left(e_{1}\right) \equiv E_{x i e t}\left(e_{2}\right)\right)
$$

From all of this we can prove thas if the Evening Star rises then the Moraing Star riaes, but we cannot prove from John's belief that the Eveaing Star rises that John believen the Moraing Star rises. If John knows the Morning Stap and the Eveaing Star are identical, and be knowo axiom (17), then his belief that the Morning Star rises ean be proved as one would prove bis betief in the consequenees of any otber oyilorism whom premises be believed, in sceordanee with s treabment of reasoning about belief developed in a longer vernion of this pater.

This solution is in the spirit of our whole represeatacional approsech in thas it forees us to be painfully explicit about everythung. The notation does no magic for us. There is a sigaificant cose associaced with this solution. however. When proper names are represented as predicates and not a consenke, the astural way to state the uniquenese of proper names is by meana of axioms of the following sort:

$$
(\forall x, y) \text { Evening-Star }(z) \wedge \text { Evening-Star }(y) \supset x=y
$$

But since from the axioms for rw-identical we can show that Evering Star $(M S)$, it would foilow that $M S=E S$. We must thus restate the axiom for the uniqueness of proper aames as

$$
\begin{gathered}
(\forall x, y) \text { Evening-Slar }(x) \wedge \text { Evening-Slar }(y) \\
\supset \text { ro-idenlical }(x, y)
\end{gathered}
$$

A similar modification must be made for functions. Since we are using only predicaces, the uniqueness of the vaiue of a function must be excoded with an axiom like

$$
(\forall x, y, z) \text { father }(x, z) \wedge \text { father }(y, z) \supset x=y
$$

If $z$ and $y$ are both fathers of $z$, then $x$ and $y$ are the same. This would have to be replaced by the axiom

$$
(\forall x, y, z) \text { father }(x, z) \wedge \text { father }(y, z) \supset \text { rv-identical }(x, y)
$$

The very common problems involving reasoning about equality, which can be done efficieotly, are thus translated into problems involving reasoning about the predicate rw-identical, which is ver cumbersome.

One way to view this second solution is as a fix to the first solution. For " $\Rightarrow$ " we substitute the relation rw-identical, and by means of axiom schema (17), we foree substitutions to propagate to the eventualities they occur in, and we force the distinction between referentially transparent and referentially opaque predicates to be made explieitly. It is thus an indirect way of rejecting Leibniz' Law.

The third solution is to say that 'the Evening Star' in sentence (14) does not really refer to the Evening Star, but to some abatract entity somehow related to the Eveaing Star. That is. sentence (14) is really an example of metonymy. This may seem counterintuitive, and even bizarre, at first blush. But in fact the most widely accepted classical solutions to the problem of identity are of this flavor. For Frege (1892) "the Evening Star" in seatence (14) does not refer to the Evening Star but to the cenue of the phrase "the Evening Star". In a more recent approsech. Zalta (1983) takes such noun phrases to refer to abscrect objects" related to the real object. In both approaches soun phraces in intenvional contexts refer to senses or abstract objecta, while otber noun phrasen refer to actual entities. and so it is aecesory to specify which predicates are intensionai. In a Montagovian approach, "the Evening Star" would be taken to refer to the intension of the Evening Star, not its extension in the real world, and noun phrases would always be taken to refer to intensions, although for nonintensional predicates there would be meaning postulates thas make this equivalent to reference to extensions.

Thus, in all these approsches intensional and extensional predicates must be distinguished explicitly, and noun pbrases in inteanional contexts are syotematically interpreted metonymically.

It would be eay enough in our framewort to implement these approsebes. We can define sunction $a$ of three arguments - the actual entity, the cornizer, and the condition used to describe the entity - that returns the sense, or intension, or abstract entity, corresponding to the actual entity for that cogaizer and that condicion. Sentence (14) would be represented. not as (16), bue 2

\section{(18) Believe $\left(J, P_{1}\right) \wedge$ rised $\left(P_{1}, \alpha\left(E S, J, Q_{1}\right)\right) \wedge$ believe( $\left.J, Q_{1}\right)$ $\wedge$ Eveningstar' $\left(Q_{1}, E S\right)$}

I tend to prefer to think of the value of $\alpha\left(E S, J, Q_{1}\right)$ as an abstract entity. Whatever it is, it is necessary that the value of $a\left(E S, J, Q_{1}\right)$ be something different from the value of $\alpha\left(E S, J, Q_{2}\right)$ where Morning-Slar' $\left(Q_{2}, E S\right)$. That is, different abstract objects must correspond to the condition $Q_{1}$ of being the Evening Star and the condition $Q$ : of being the Moming Star. It is because of this feacure that we escape the problem 
of intersubatitutivity of identicals, for subatitution of $M S$ for $E S$ in (18) yields "... $\wedge$ rise' $\left(P_{1}, a\left(M S, J, Q_{1}\right)\right) \wedge$..." racher than -...A rise $\left(P_{1}, a\left(M S, J, Q_{2}\right)\right) \wedge \ldots$. , which would be the representation of sentence (15).

The difficulty with this approseb is that it makes the interpretacion of noun phrwes dependent on their embedding context:

Intensional context $\rightarrow$ metonymic interpretacion

Extensional context - nonmetonymic interpretation

It thus vioiates, though not seriously, the naive compositionality that I have been at so many pains to preserve. Metonymy is a very common phenomenon in discourse, but I prefer to thin't of it as oceurring irregularly, and not as signalled systematically by other elements in the sentence.

Having laid out the three poasible solutions and their shortcomings, I find thas I would like to avoid the problem of identity altogether. The thind approach sugsests a ruse for doing so. We can assume that, in general, (16) is the representation of sentence (14). We invoke no extra complications where we don't have to. When, in interpreting the text, we encounter a difficulty resulting from the problem of identity, we can go back and revice our incespretation of (14), by asouming the reference must have been a metonymic one to the abstract entity and not to the actual entity. In thoce cases it would be as if we are saying. John couldn't believe about the Evening Star itself that it is rising. The paradox shows that be is insufficiently acquainted with the Evening Star to refer to it directly. He must be talking about an abotrect entity related to the Evening Star." My guess is that we will not have to resort to this ruse often, for I suspect the problem rarely arises in cetual discourse interpretacion.

\section{The Role of Semantics}

Let me elow by making some comments about ways of doing semanties. Semanciea is the attempted specification of the re lation between language and the wortd. However, this requires a theory of the world. There is a spectrum of choices one can make in this regard. At one end of the speetrum - let's say the right end - one ean adopt the "eorrect" theory of the world, the theory given by quantum mechaniea and the other sciences. If ore does this, semantie beeomen imponible because it is ao les than all of science, a lace thes bas led Fodor (1980) to expreas some despair. There's too mueh of a minmaceh between the way we view the world and the woy the worid really is. As the left end. one can anume a theory of the worid that is isomorphic to the way we talk about it. What I heve been doing in this paper, in fact, is an effort to wort out the detaila in such a theory. In this case, semantica becomes very aeariy trivial. Most activity in semanties today is slightly to the righs of the extreme left end of this spectrum. One make certain noumptions about the asture of the wortd thas elonely redeet languase, and doean't make certain otber ecumptions. Where one hes failed to make the secessary socumptions, purziles appear, and semanties becomes an effort to solve those puzztes. Nevertbeies, it fails to move far enough away from language to represent signifieant progrese towand the right end of the spectrom. The pasition $I$ advocate is that there is do reason to make our task more diffeult. We will bave puzziles enough to solve when we get to discourse.

Achnowiedgemente
I have profited from discussions about this work with Chris Menzel, Bob Moore, Stan Rosenschein, and Ed Zalta. This researeh was supported by NIH Grant LM03611 from the National Library of Medicine, by Grant IST-8209346 from the Nacional Seience Foundation, and by a gift from the Systems Developmeat Foundacion.

\section{References}

[1] Bobrow, Daniel G. and Terty Winograd, 1977. An Overview of KRL, A Knowledge Representation Language", Cognilive Science, vol. 1, pp. 3-46.

[2] Davidson, Donald, 1967. The Logical Form of Action Sentences", in N. Rescher, ed., The Logic of Decision and Action. pp. 81-95, University of Pittsburgh Press. Pittsburgh, Pennsylvania.

[3] Fodor, J. A., 1980. "Methodological Solipsism Considered as a Research Strategy in Cognitive Psychology", The Behaviond and Brain Sciences, vol. 3, no. 1, March, 1980.

[4] Frege, Gotlieb, 1892. "On Sense and Nominatum", in H. Feigel and $W$. Sellars, ed., Resdings in Pholosophical t nalyses. pp. 85-102, Appleton-Century-Croft, Inc., New York. 1949.

[5] Hayes, Pacrick J., 1979. The Logic of Frames", in D. Wetzing, ed., Frame Conceptions and Text Understanding, pp. 16-61, Walter de Gruyter and Company.

(6) Headrix. Gary G., 1975. Extending the Utility of Semantic Networks Through Partitioning", Advance Papers, Inter. national Joint Conference on Artificial Intelligence. Tbilisi, Georgien SSR, pp. 115-121, September, 1975.

[7] Hobbs, Jerry R, 1983. "An Improper Treatment of Quancifcation in Ordinary English", Proceedings of the s1st tnnual Meeting, Association for Computational Lingusstics, pp. 3i63. Cambridge, Massachusetts, June, 1083.

[8] McCartby, John, 1977. "Epistemological Problems of Artificivd Intelligerce", Proceedings, International Joint Conference on Artifieial Intelligence, pp. 1038-1044, Cambridge, Massachusetts, Ausast, 1977.

[9] Minaby, Marrin, 1975. ¿A Framewort for Representing Knowledge", in Patrick H. Winston, ed., The Psychology of Computer Vievion pp. 211-277, MeGraw-Hill.

(10) Moore, Robert C., 1980. “Reasoning about knowledge and Actinn", SRI Interactional Technical Report 191, October. 1980.

[11] Moore, Robert C. and Gary G. Hendrix, 1982. "Computational Modele of Betief and the Semantics of Belief Sentences", in S. Petess and E. Sanrinen, eds., Processes, Beliefs, and Questions, pp. 107-127, D. Reidel Publishing Company.

[12] Quilian, M. Rose, 1968. "Semantic Memory", in Marvin Minsty, ed, Semanatic Information Processing, pp. 227-270, MIT Press, Cambridse, Massachusetts.

[13) Quine, Willard V., 1953. "On What There Is", in From a Logiead Point of Vien, pp. 1-19, Harvard University Press. Cambridse, Mascectrusetes. 
[14] Quine, Willard V., 1956. "Quantifiers and Propositional Attitudes", Journal of Philosophy, vol. 53.

[15] Reichenbach, Hans, 1947. Elements of Symbolic Logic, The MacMillan Company.

[16] Schmolze, J. G. and R. J. Brachman, 1982. "Summary of the KL-ONE Language", in Proceedings, $1981 K L$.ONE Workshop, pp. 231-257, Fairchild Laboratory for Artificial Intelligence Researeh, Palo Alto, California.

(17) Simmons, Robert F., 1973. "Semantic Networks: Their Computation and Use for Understanding English Sentences", in Roger Schank and Kenneth Colby, eds., Computer Models of Thought and Language, pp. 63-113, W. H. Freeman: San Francisco.

(18) Zalta, Edward N., 1983. Abstract Objects: An Introduction to Ariomatic . Metaphysics, D. Reidel Publishing Company: Dordreebt, Netheriands. 